\title{
Bronchoscopic treatment of a bronchopleural fistula after pneumonectomy
}

\author{
Vanessa Menezes, MD, ${ }^{\mathrm{a}, \mathrm{b}}$ Stephan Soder, MD, ${ }^{\mathrm{a}, \mathrm{b}}$ Sulaiman Kadadah, MD, ${ }^{\mathrm{a}, \mathrm{b}}$ Jean-Bernard Masson, MD, \\ Edwin Lafontaine, MD, ${ }^{a}$ and Moishe Liberman, $\mathrm{MD}, \mathrm{PhD},{ }^{\mathrm{a}, \mathrm{b}}$ Montreal, Quebec, Canada
}

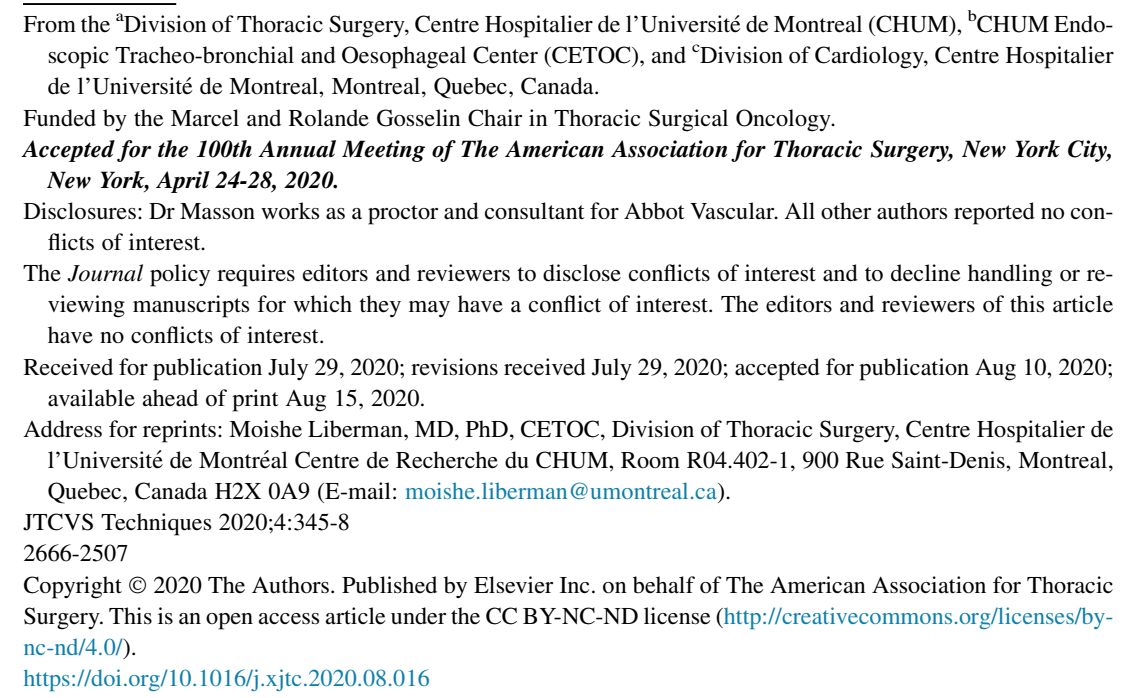

Video clip is available online.

Left mainstem bronchopleural fistula (BPF) is a morbid complication after pneumonectomy. There is a lack of consensus on how to best manage small BPFs in stable, nonseptic patients due to the high operative morbidity and mortality. ${ }^{1}$ Different bronchoscopic techniques, including glue, cellulose patches, coils, Watanabe spigots, and endobronchial valves, ${ }^{2}$ have been used for the nonoperative treatment of BPFs, with varying success rates. ${ }^{3}$ Here, we present a case of a small left mainstem BPF that was successfully closed with an Amplatzer Vascular Plug II (AVPII; AGA Medical Corp/St Jude Medical, St Paul, Minn).

\section{CLINICAL SUMMARY}

A never-smoker, 64-year-old female patient with no previous medical history underwent a left intrapericardial pneumonectomy for hilar non-small cell lung cancer after induction immunotherapy. A decision to convert from videothoracoscopy to thoracotomy was made after visualization of multiple fixed pleural adhesions in the posterior mediastinal and apical space. A pedicled intercostal muscle flap was harvested before the insertion of the rib spreader and was used intraoperatively to buttress the left mainstem bronchial stump. The intrapericardic approach facilitated (Figure 1, B).

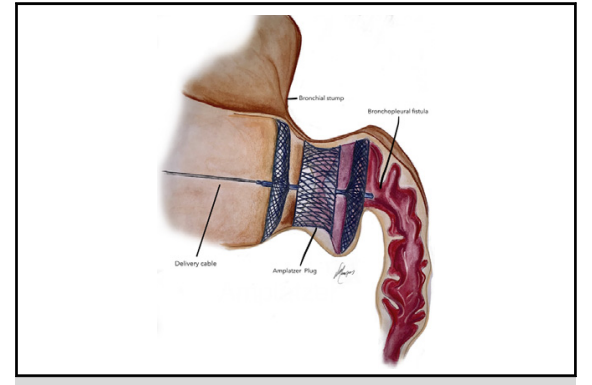

An Amplatzer Vascular Plug occluding a partial bronchopleural fistula after pneumonectomy.

\section{CENTRAL MESSAGE \\ The management of postpneu- monectomy BPF is challenging. Amplatzer devices are alterna- tives in an endoscopic, conser- vative treatment for bronchopleural fistula closure in stable, nonseptic patients.}

See Commentaries on pages 349 and 351 .

the safe exposition of vascular and bronchial structures and mediastinal adenopathies dissection due to residual inflammation related after immunotherapy.

Two months after surgery, the patient developed a chronic, productive cough, and follow-up radiography of the chest found the left chest, which had previously been filled, to have lost the majority of the fluid in the postpneumonectomy space. Flexible bronchoscopy was performed, confirming the presence of a small BPF (Figure 1, A). The patient was clinically stable, afebrile, and nonseptic. A computed tomography scan was performed, which showed a partially filled left hemithorax, an air-fluid level, and indirect radiographic signs that suggested a left BPF

Given the small size of the BPF and the clinical picture of the patient, a conservative strategy was chosen as a first attempt at treatment. A left pigtail catheter was inserted into the left pleural space under ultrasound guidance and intravenous antibiotics were started. 

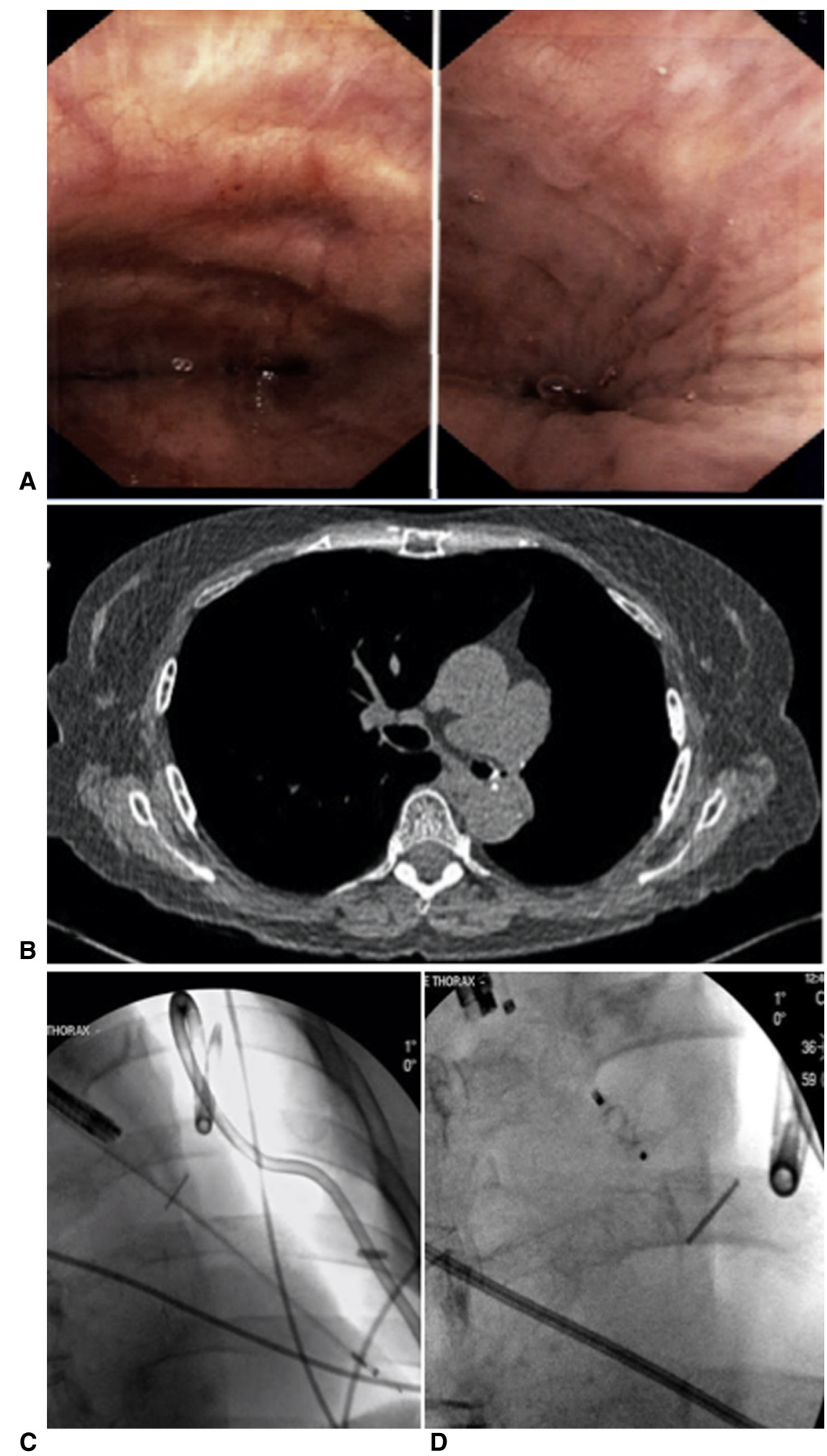

FIGURE 1. A, Primary endoscopic evaluation by bronchoscopy showing a small medial bronchopleural fistula in the postpneumonectomy stump. B, Preinterventional computed tomography showing an air column after stump staple line that suggested a left bronchopleural fistula. C, Bronchoscopy combined with fluoroscopy to identify the proper passage of the guidewire through fistula into the pleural space (with a pleural catheter inside). D, Fluoroscopy image showing an Amplatzer Plug II device appropriately positioned through bronchial stump. 


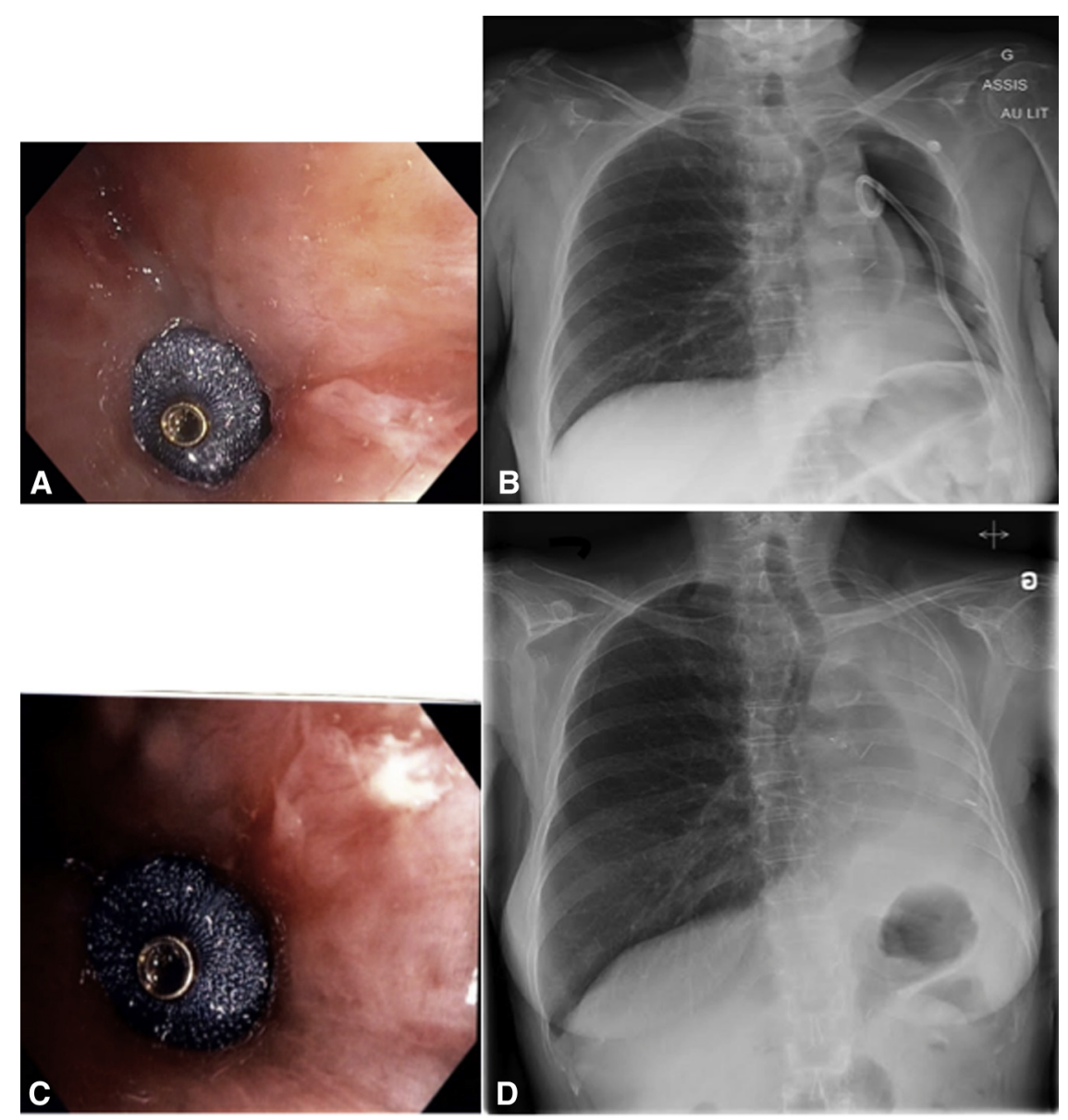

FIGURE 2. A, Bronchoscopic view of an Amplatzer Vascular Plug II positioned through a medial bronchopleural fistula postpneumonectomy. B, Immediate post-Amplatzer device placement chest radiographic control demonstrating no complications related to the procedure (left pleural catheter was placed before the bronchoscopy). C, Bronchoscopy done after 6 months of the procedure showing no displacement of the Amplatzer device in the bronchial stump. $\mathrm{D}$, Chest radiographic control after 6 months of the intervention demonstrating left hemithorax completely filled with fluid.

With the patient under conscious sedation, flexible video bronchoscopy (BF-1TH190; Olympus, Center Valley, Pa) showed a 2-mm BPF in the medial aspect of the left mainstem bronchial stump. A guidewire $(0.035$ inch $\times 180 \mathrm{~cm})$ was inserted into the BPF. Fluoroscopy was used to assist the guidewire position into the pleural space (Figure 1, C). A 6-Fr "Envoy" guiding catheter was introduced over the guidewire to deploy an AVPII (AGA Medical Corp/St Jude Medical) across the BPF under real-time fluoroscopic (Figure 1,D) and bronchoscopic (Figure 2, A, and Video 1) guidance. Follow-up radiography of the chest showed proper plug placement (Figure 2, B).

Four days later, the pleural pigtail catheter was removed. The patient was discharged on oral antibiotics on day 7 following AVPII insertion. No additional endoscopic interventional procedures were necessary. Radiographic follow-up at 6 months following AVPII insertion showed the left hemithorax completely filled with fluid
(Figure 2,D) and bronchoscopy confirmed proper AVPII position and lack of complications related to the procedure (Figure 2, C).

\section{DISCUSSION}

Amplatzer devices are self-expandable disks popular in interventional cardiology. They are mostly used for the treatment of congenital septal malformations. Modifications in the size and design of these devices have expanded their applicability to multiple percutaneous transcatheter closures, with the Amplatzer Vascular Plugs currently being used in peripheral embolization. ${ }^{3,4}$ Previously published reports have also documented the use of Amplatzer devices in BPF closure after pneumonectomy. ${ }^{5}$

The management of postpneumonectomy BPF is challenging. This case adds to the growing literature reporting on endoscopic, conservative management of this morbid complication and demonstrates the ease, feasibility, and 


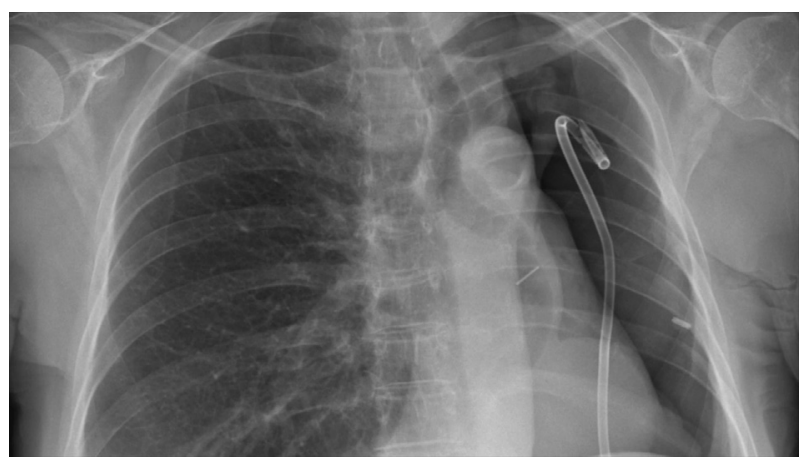

VIDEO 1. Interventional bronchoscopy combined with fluoroscopy for placement of an Amplatzer Plug device for endoscopic treatment of a bronchopleural fistula after pneumonectomy. Video available at: https://www. jtcvs.org/article/S2666-2507(20)30391-6/fulltext. success of conservative management of a BPF using an AVPII under conscious sedation guided by flexible bronchoscopy and real-time fluoroscopy.

The patient authorized the publication of this manuscript by informed consent.

\section{References}

1. Fruchter O, Kramer MR, Dagan T, Raviv Y, Abdel-Rahman N, Saute M, et al. Endobronchial closure of bronchopleural fistulae using Amplatzer devices: our experience and literature review. Chest. 2011;139:682-7.

2. Lois M, Noppen M. Bronchopleural fistulas: an overview of the problem with special focus on endoscopic management. Chest. 2005;128:3955-65.

3. Klotz LV, Gesierich W, Schott-Hildebrand S, Hatz RA, Lindner M. Endobronchial closure of bronchopleural fistula using Amplatzer device. J Thorac Dis. 2015;7: $1478-82$.

4. Lopera JE. The Amplatzer Vascular Plug: review of evolution and current applications. Semin Intervent Radiol. 2015;32:356-69.

5. Marwah V, Rajput AK, Madan H, Garg Y. Closure of chronic bronchopleural fistula using atrial septal occluder device. J Bronchol Intervent Pulmonol. 2014;21:82-4. 